\title{
Management of Chronic Knee Pain Caused by Postsurgical or Post-traumatic Neuroma of the Infrapatellar Branch of the Saphenous Nerve.
}

Gilad J. Regev ( $\sim$ giladre@tlvmc.gov.il )

Tel Aviv Sourasky Medical Center https://orcid.org/0000-0002-4079-1068

Dvir Ben Shabat

Tel Aviv Sourasky Medical Center

Morsi Khashan

Tel Aviv Sourasky Medical Center

Dror Ofir

Tel Aviv Sourasky Medical Center

Khalil Salame

Tel Aviv Sourasky Medical Center

\section{Yuval Shapira}

Tel Aviv Sourasky Medical Center

\section{Ron Kedem}

Tel Aviv Sourasky Medical Center

Zvi Lidar

Tel Aviv Sourasky Medical Center

\section{Shimon Rochkind}

Tel Aviv Sourasky Medical Center

\section{Research article}

Keywords: Infrapatellar branch, saphenous nerve, neuroma, neurolysis

Posted Date: March 2nd, 2021

DOl: https://doi.org/10.21203/rs.3.rs-255293/v1

License: (1) (i) This work is licensed under a Creative Commons Attribution 4.0 International License. Read Full License 


\section{Abstract}

Purpose: Injury to the infrapatellar branch of the saphenous nerve (IBSN) is a relatively common complication after knee surgery that can interfere with patient satisfaction and functional outcome. In some cases, trauma to this nerve can lead to the formation of a painful neuroma. The purpose of this study is to report the results of surgical treatment in a series of patients with IBSN painful neuroma.

Methods: A retrospective review was made of 37 patients undergoing resection of IBSN neuroma at our institution, after failure of non-operative treatment for a minimum of 6 months.

Results: Following surgery, $80 \%$ of the patients experienced statistically and clinically significant improvement in pain levels. The average NRS Pain score improved from $9.43 \pm 1.34$ to $5.12 \pm 3.33$ $(p<0.001)$. The EQ-5D functional score improved from $10.48 \pm 2.33$ to $7.84 \pm 2.19$. Overall patient reported satisfaction from the surgical results was good to excellent in $72 \%$ of patients. Non-favorable prognosis was found to correlate with older age, multiple prior orthopedic surgeries at the knee area and failed prior attempts to resect an IBSN neuroma.

Conclusion: We conclude that in patients suffering from IBSN painful neuroma, surgical resection results in a favorable prognosis.

\section{Introduction}

The infra-patellar branch of the saphenous nerve (IBSN) is a small nerve that originates at the medial portion of the knee and provides sensation to the area of the tibial tuberosity without motor component. $[6,7]$ The saphenous nerve, a branch of the femoral nerve, accompanies the femoral artery in the adductor canal; once exiting this canal, the nerve travels behind the medial aspect of the knee where the IBSN branches off. The ISBN then emerges from the posterior aspect of the sartorius muscle at its distal end, or close to the tendons of the gracilis muscle and semitendinosus muscles. [10] Figure 1.

Injury to the IBSN has become increasingly common due to the popularity of arthroscopic knee surgery associated with ligament harvesting[2] and total knee arthroplasty. [3] Loss of sensation over the anterior aspect of the knee secondary to knee surgery can vary. Some studies reported that IBSN injury ranges between $22.2 \%$ and $70 \%$ following different surgeries at the knee area.[4,11,13] Moreover, trauma to the IBSN can result in the formation of a painful neuroma, analogous to that following injury to other peripheral nerves that have a cutaneous distribution.[14] As a result, patients usually complain of a burning sensation and hypersensitivity that is located at the cutaneous distribution of the IBSN..[15]

Surgical treatment of painful IBSN neuroma had been previously reported.[1,3,5] However, due to the relative rarity of this condition, previous studies included mainly case reports or small case series. As such, the optimal surgical approach and functional outcome of these patients following surgery are not yet -understood. 
The purpose of this case series is to report pain and functional outcomes of a consecutive series of patients with chronic knee pain due to neuroma of the IBSN who underwent surgical treatment in our institute. Furthermore, we investigated the correlation between different demographic and preoperative clinical variables with postoperative clinical outcomes.

\section{Methods}

A retrospective review was made of all patients who underwent resection of painful IBSN neuroma at our institution. We included patients with a painful IBSN neuroma secondary to prior surgery or trauma in the knee area, who had failed a trial of non-operative treatment for a minimum of 6 months. Preoperative assessment included demographic data, and a history of surgical intervention or trauma in the distribution of the saphenous nerve. Physical examination findings that were supportive of IBSN related pain included pain isolated to the distribution of the anteromedial aspect of the knee, tenderness elicited on palpation of the medial femoral condyle (Tinel sign) and associated paresthesia along the nerve distribution. Selective nerve block using a local anesthetic agent, was performed on selected patients to confirm clinical suspicion of neuropathic pain. Additionally, when the diagnosis of IBSN was uncertain, patients underwent a sensory nerve conduction velocity (NCV) study or an ultrasound imaging of the knee area in an effort to demonstrate the subcutaneous neuroma.

Measured clinical outcomes included: hospital length of stay (LOS), early postsurgical complications and revision surgery. Patient-reported outcomes included: numerical rating scale (NRS) for leg pain before surgery and post-operatively, need for sustained pain treatments and patients' satisfaction and healthrelated quality of life EQ-5D-3L instrument. The EQ-5D questionnaire consists of five dimensions including mobility, self-care, usual activities, pain and anxiety/depression. Each domain is rated according to three levels of severity: no problems (1 point), some or moderate problems ( 2 points), and severe problems (3 points). Phone interviews were conducted by one of the authors: (D.BS). All patients were operated on by the senior author (SR).

\section{Surgical technique:}

An incision was done at the medial distal part of the thigh ( $3 \mathrm{~cm}$ above the knee) and continued $3 \mathrm{~cm}$ along the medial surface of the knee. The deep fascia to the vastus medialis was opened and the muscles were retracted. Under a surgical microscope, the saphenous nerve and its infrapatellar branch were identified, and neurolysis was performed on the infrapatellar nerve.

Surgical intervention was mainly directed to the removal of the neuroma and neurolysis. Proximal transection of the IBSN close to its origin from the saphenous nerve was performed. Then, Marcaine $0.5 \%$ was injected in the proximal nerve stump epineurally and the nerve stump was implanted firmly into an adjacent skeletal muscle and secured with sutures.

Statistical analysis: 
The paired T-test parametric analysis was used to compare pre- and postoperative pain and mean EQ-5D. Correlation analysis was used to correlate the surgical outcome with the following variables: age, gender, prior surgery, and prior resection of a neuroma. The data was analyzed using IBM corporation and other (8) 1989, 2019, Statistical Package for Social Sciences (SPSS, Inc., Chicago, IL USA) version 24.0. A pvalue less than 0.05 is considered statistically significant.

\section{Ethical considerations}

Approval for this research was obtained from the Institutional Research Ethics Board

\section{Results}

Thirty-seven patients (17 females, 20 males) underwent resection of an IBSN neuroma at our institution between the years 2001 and 2015. Among them, 25 patients were available to answer a follow-up selfreported functional outcome questionnaire. The average age was $38.9 \pm 12.5$ years and average follow-up from surgery was $94 \pm 52.9$ months. Injury to the IBSN resulted from a previous orthopedic surgery in 20 patients, in 13 of them this was an arthroscopic surgery of the knee, 5 underwent anterior cruciate ligament (ACL) reconstruction and 4 open reduction and fixation of a fracture. Three patients had undergone previous vascular surgery involving either saphenous vein harvesting or a femoral-popliteal arterial graft. Six patients were post resection of a tumor from the area of the distal femur or proximal tibia. These included two osteochondromas, one schwannoma, one benign fibrous histiocytoma, one glomus tumor and one peripheral Schwannoma.

In the remaining 8 patients, a precipitating trauma or skin infection to the lower limb caused the initial nerve injury consisting of a blunt trauma to the leg in 5 , skin laceration in 2 patients and Erysipelas in one patient. All patients had failed a trial of non-operative treatment for a minimum of 6 months and 20 patients reported undergoing numerous surgeries at the knee area prior to their referral to our institute. Six patients were after two prior surgeries, 3 had had three and 1 patient had undergone 4 prior knee surgeries. Three of these patients, also reported undergoing a prior unsuccessful resection of an IBSN neuroma. Table 1.

Preoperative sensory NCV study focusing on the infrapatellar nerve was done in 27 patients. The NCV study was able to locate a conduction impairment of the saphenous nerve and the IBSN in $89 \%$ of the cases. Additionally, ultrasound imaging of the nerve was done in a subgroup of 15 patients, of them, only in 7 patients the neuroma was identified prior to surgery. All patients were operated at a same day surgery service and were released from the hospital in the evening of the surgery. No complications were noted during surgery. One patient developed a postoperative wound infection that was treated by surgical wound revision and an antibiotic treatment.

Following surgery, statistically and clinically significant improvement in pain was seen in $80 \%$ of patients. The NRS pain score improved from $9.4 \pm 1.3$ to $5.1 \pm 3.3$ ( $P<0.01)$. Nevertheless, $52 \%$ of patients reported that they continued to use analgesic treatment regularly and $36 \%$ continued pain clinic treatments. 
Five patients $(20 \%)$ underwent revision surgery in our institute due to recurrent knee pain. The time interval between the primary and the revision surgery was $21.4 \pm 17.1$ months.

The EQ-5D functional score improved from $10.48 \pm 2.33$ to $7.84 \pm 2.19(P<0.01)$. Overall patient reported satisfaction from the surgical results was good in $72 \%$ of patients. Table 2 .

Using regression analysis, the following variables were found to correlate with favorable pain improvement: younger age, male gender, higher level of self-reported anxiety and depression status, preoperative pain level and mobility limitations. A non-favorable outcome was correlated with the following variables: high number of prior surgeries, prior resection of a IBSN neuroma and higher level of limitations in activity and self-care $(p<0.001)$. Figure 2

Favorable functional outcome improvement was correlated with younger age, male gender, high level of preoperative anxiety and depression. Non-favorable improvement was correlated with high number of prior surgeries, and higher levels of activity limitation $(p=0.001)$. Figure 3

Other variables including: preoperative pain, limitations in mobility and self-care limitation, side of surgery and prior surgery for resection of a neuroma were not associated with improvement in patients' functional outcome.

\section{Discussion}

Painful neuroma of the IBSN was first reported by Blazina et al. in 1968.[1] Formation of IBSN neuroma following trauma or prior surgery could result in severe and debilitating pain which is often difficult to manage. Due to the pain, some patients are severely limited in their activities of daily living and quality of life. $[9,15]$

Previous studies reported that injury to the IBSN results most commonly from orthopedic surgeries of the knee joint.[5] This was also found in the current series. However, our series included a wide array of additional pathologies, including: vascular surgeries, resection of benign tumors and trauma that can result in injury to the IBSN and subsequent formation of a painful neuroma.

When conservative treatments fail to provide adequate pain relief, selective denervation with resection of the neuroma should be considered. Neurolysis for IBSN entrapment was first described by House et al. [8] who reported excellent outcome in 4 patients that suffered from medial knee pain without prior surgery. Dellon et al.[3] reported their experience with IBSN denervation for treatment of postoperative knee pain following total knee arthroplasty.

One of the most important elements of selective denervation is determining which patients are candidates for the procedure. This requires a thorough history, physical examination by an orthopedic surgeon and by a specialist in peripheral nerve surgery. Previous studies advocated the use of local lidocaine nerve block to establish the diagnosis of IBSN neuroma[5], while others questioned the predictive value of this trial.[12] In our patients, whenever the diagnosis of IBSN neuroma was uncertain, a 
sensory nerve conduction study and ultrasound imaging of the knee area were done in an effort to demonstrate the subcutaneous neuroma. Our results indicate that although ultrasound imaging was able to demonstrate a pathology in only $47 \%$ of the cases, specific nerve conduction study was found to have good sensitivity and could detect a nerve conduction abnormality in $89 \%$ of the cases. However, It is important to note that such specific nerve conduction studies are usually not available in routine electrophysiological diagnostic tests and require a neurophysiologist with experience to perform this examination.

Despite meeting the criteria for selective denervation, not all patients benefit from this procedure. In the current study, $72 \%$ of the patients were satisfied with the surgical outcome. Of the remaining $28 \%$ that did not improve from surgery $13 \%$ underwent a revision surgery. Although similar success rates were published in earlier case series $[5,14]$ it is important to note that $54 \%$ of the patients in our cohort had undergone multiple knee surgeries before they were referred to our treatment. Moreover, four patients had undergone prior failed neurolysis of the IBSN. Our study identified several risk factors that were correlated with non-favorable prognosis, among them: older age, multiple prior orthopedic surgeries at the knee area and failed prior attempts to resect the IBSN neuroma. We recommend that these risk factors be appreciated whenever surgical intervention is considered.

\section{Conclusions}

We suggest that IBSN neuroma should be suspected in patients who develop chronic neuropathic medial knee pain following orthopedic surgeries or trauma to the knee joint. In properly diagnosed and selected patients, surgical neurolysis and resection of painful IBSN neuroma provides a significant and longlasting pain improvement in the majority of patients. Furthermore, this improvement also leads to a significant improvement in patients reported quality of life.

\section{List Of Abbreviations}

IBSN- Infrapatellar Branch of the Saphenous Nerve

NCV - Nerve Conduction Velocity

LOS - Hospital Length of Stay

ACL - Anterior Cruciate Ligament

NRS - Numerical Rating Scale

\section{Declarations}

\section{ACKNOWLEDGEMENTS}


The authors thank Dr. Dalia Gut-Regev and Ms. Noa Regev for their help with the preparation of this manuscript.

\section{Availability of data and materials}

All data generated or analyzed during this study are included in this published article.

\section{Funding}

This research did not receive any specific grant from funding agencies in the public, commercial, or notfor-profit sectors.

\section{Contributions}

Regev G.J analyzed the data and drafted the manuscript. Ben Shabat D collected the data and drafted the manuscript. Khashan M, Ofir D, Salame K, assessed and collected the data. Kedem R preformed statistical analysis of the data. Shapira $Y$ followed up the patients, collected the data. Lidar $Z$. participated in the design of the study. Rochkind S participated in the design of the study, performed the surgery, and revised the manuscript. All authors read and approved the final manuscript.

\section{Ethics declarations}

\section{Ethics approval and consent to participate}

This retrospective review study involving human participants was in accordance with the ethical standards of the institutional and national research committee and with the 1964 Helsinki Declaration and its later amendments or comparable ethical standards. The study was approved by the medical ethics committee of our hospital. Informed consent was obtained from all individual participants included in the study.

\section{Consent for publication}

Not applicable.

\section{Competing interests}

The authors declare that they have no competing interests. 


\section{References}

1. Blazina ME, Cracchiolo A, 3rd (1968) Neurilemoma of the infrapatellar branch of the saphenous nerve. A case report. Clin Orthop Relat Res 60:213-215

2. Cohen SB, Flato R, Wascher J, Watson R, Salminen M, O'Brien D, Tjoumakaris F, Ciccotti M (2017) Incidence and Characterization of Hypoesthesia in the Distribution of the Infrapatellar Branch of the Saphenous Nerve after Anterior Cruciate Ligament Reconstruction: A Prospective Study of PatientReported Numbness. J Knee Surg. doi:10.1055/s-0037-1605559

3. Dellon AL, Mont MA, Krackow KA, Hungerford DS (1995) Partial denervation for persistent neuroma pain after total knee arthroplasty. Clin Orthop Relat Res:145-150

4. Dellon AL, Mont MA, Mullick T, Hungerford DS (1996) Partial denervation for persistent neuroma pain around the knee. Clin Orthop Relat Res:216-222. doi:10.1097/00003086-199608000-00027

5. Ducic I, Levin M, Larson EE, Al-Attar A (2010) Management of chronic leg and knee pain following surgery or trauma related to saphenous nerve and knee neuromata. Ann Plast Surg 64:35-40. doi:10.1097/SAP.0b013e31819b6c9c

6. Ebraheim NA, Mekhail AO (1997) The infrapatellar branch of the saphenous nerve: an anatomic study. J Orthop Trauma 11:195-199

7. Henry BM, Tomaszewski KA, Pekala PA, Ramakrishnan PK, Taterra D, Saganiak K, Mizia E, Walocha JA (2017) The Variable Emergence of the Infrapatellar Branch of the Saphenous Nerve. J Knee Surg 30:585-593. doi:10.1055/s-0036-1593870

8. House JH, Ahmed K (1977) Entrapment neuropathy of the infrapatellar branch of the saphenous nerve. Am J Sports Med 5:217-224. doi:10.1177/036354657700500509

9. Kachar SM, Williams KM, Finn HA (2008) Neuroma of the infrapatellar branch of the saphenous nerve a cause of reversible knee stiffness after total knee arthroplasty. J Arthroplasty 23:927-930. doi:10.1016/j.arth.2007.07.019

10. Kerver AL, Leliveld MS, den Hartog D, Verhofstad MH, Kleinrensink GJ (2013) The surgical anatomy of the infrapatellar branch of the saphenous nerve in relation to incisions for anteromedial knee surgery. J Bone Joint Surg Am 95:2119-2125. doi:10.2106/JBJS.L.01297

11. Koch G, Kling A, Ramamurthy N, Edalat F, Cazzato RL, Kahn JL, Garnon J, Clavert P (2017) Anatomical risk evaluation of iatrogenic injury to the infrapatellar branch of the saphenous nerve during medial meniscus arthroscopic surgery. Surg Radiol Anat 39:611-618. doi:10.1007/s00276016-1781-z

12. Malessy MJA, de Boer R, Munoz Romero I, Eekhof JLA, van Zwet EW, Kliot M, Dahan A, Pondaag W (2018) Predictive value of a diagnostic block in focal nerve injury with neuropathic pain when surgery is considered. PLoS One 13:e0203345. doi:10.1371/journal.pone.0203345

13. Mochida H, Kikuchi S (1995) Injury to infrapatellar branch of saphenous nerve in arthroscopic knee surgery. Clin Orthop Relat Res:88-94 
14. Nahabedian MY, Johnson CA (2001) Operative management of neuromatous knee pain: patient selection and outcome. Ann Plast Surg 46:15-22. doi:10.1097/00000637-200101000-00004

15. Tennent TD, Birch NC, Holmes MJ, Birch R, Goddard NJ (1998) Knee pain and the infrapatellar branch of the saphenous nerve. J R Soc Med 91:573-575

\section{Tables}

Table 1. Patient demographic and clinical presentation.

\begin{tabular}{|c|c|c|c|c|c|c|c|c|c|c|c|c|}
\hline $\begin{array}{l}\text { Patient } \\
\text { number }\end{array}$ & Gender & Age & $\begin{array}{c}\text { Knee } \\
\text { Arthroscopy }\end{array}$ & ACLL Recostruction & нто & TRAUMA & ORIF & $\begin{array}{c}\text { MENISCIAL } \\
\text { TRANSPLANT }\end{array}$ & $\begin{array}{l}\text { VASCULAR } \\
\text { SURGERY }\end{array}$ & TUMOR & INFECTION & PRIOR IBSN NEUROMA RESECTION \\
\hline & & & & & & & & & & & & \\
\hline$\frac{1}{2}$ & $\mathrm{M}$ & 42 & 2 & & & & & & & & & \\
\hline$\frac{2}{3}$ & $\mathrm{M}$ & $\frac{35}{59}$ & $\frac{2}{1}$ & 1 & 1 & & & & - & & 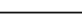 & \\
\hline 4 & $F$ & 36 & 1 & & & & & & & & & \\
\hline 5 & $\mathrm{M}$ & 42 & 2 & & & & & & & & & \\
\hline 6 & $M$ & 40 & 1 & & & & & & & & & \\
\hline 7 & $\mathrm{~F}$ & 48 & 2 & & & & & & & & & \\
\hline 8 & $M$ & 42 & & 1 & & & & & & & & \\
\hline 9 & $\mathrm{~F}$ & 37 & 2 & & & & & & & & & \\
\hline 10 & $F$ & 41 & 1 & & & & & & & & & \\
\hline 11 & $M$ & 44 & 1 & 1 & & & & & & & & \\
\hline 12 & $M$ & 46 & 4 & 1 & & & & & & & & \\
\hline 13 & $\mathrm{M}$ & 55 & 1 & & & & & 1 & & & & \\
\hline 14 & $\mathrm{~F}$ & 26 & & & & & 2 & & & & & \\
\hline 15 & $\mathrm{~F}$ & 27 & & & & & 1 & & & & & \\
\hline$\frac{16}{17}$ & $\frac{F}{M}$ & $\frac{20}{31}$ & & & & & & & 2 & 3 & & \\
\hline$\frac{17}{18}$ & $\frac{M}{F}$ & $\begin{array}{l}31 \\
24\end{array}$ & & & & & & & 2 & & 1 & \\
\hline 19 & 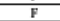 & 61 & & & & 1 & & & & 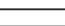 & & \\
\hline 20 & $F$ & 29 & & & & 1 & & & & & & \\
\hline 21 & $F$ & 23 & & & & & & & & 1 & & \\
\hline 22 & $\mathrm{M}$ & 23 & & & & & & & & 1 & & \\
\hline 23 & $\mathrm{M}$ & 50 & & & & & & & & & & 3 \\
\hline 24 & $\mathrm{~F}$ & 51 & & & & 1 & & & & & & \\
\hline 25 & $F$ & 32 & & & & 1 & & & & & & 1 \\
\hline 26 & $\mathrm{M}$ & 37 & 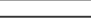 & & & & 1 & & & & & 1 \\
\hline 27 & $F$ & 17 & & & & & 1 & & & & & \\
\hline 28 & $F$ & 53 &  & & &  & & & 1 & & & \\
\hline 29 & $\mathrm{M}$ & 54 & & & & & & & 1 & & & \\
\hline 30 & $\mathrm{~F}$ & 18 & & & & 1 & & & & & & \\
\hline 31 & $\mathrm{M}$ & 36 & & & & 1 & & & & & & \\
\hline 32 & $\mathrm{~F}$ & 31 & 1 & & & & & & & 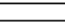 & & \\
\hline 33 & $\mathrm{M}$ & 24 & & & & 1 & & & & & & \\
\hline 34 & $\mathrm{M}$ & 31 & & & & & & & & 1 & & \\
\hline 35 & $\mathrm{~F}$ & 64 & & & & & & & & 1 & & \\
\hline 36 & $M$ & 58 & & & & & & & & 1 & & \\
\hline 37 & M & 36 & & 1 & & & & & & & & \\
\hline
\end{tabular}

Table 2. Patients outcomes 


\begin{tabular}{|c|c|c|c|}
\hline Surgical outcome $(n=25)$ & Preoperative & postoperative & $\%$ \\
\hline Pain NRS & $9.32 \pm 1.34$ & $5.12 \pm 3.33$ & \\
\hline \multicolumn{4}{|l|}{ Pain Treatments } \\
\hline Analgesic medication & & 13 & $52 \%$ \\
\hline Physiotherapy & & 10 & $40 \%$ \\
\hline Pain clinic & & 6 & $24 \%$ \\
\hline Revision surgery & & 5 & $20 \%$ \\
\hline \multicolumn{4}{|l|}{ Satisfaction from surgery } \\
\hline Very satisfied & & 12 & $48 \%$ \\
\hline Moderately satisfied & & 6 & $24 \%$ \\
\hline Not satisfied & & 7 & $28 \%$ \\
\hline \multicolumn{4}{|l|}{$E Q 5 D$} \\
\hline \multicolumn{4}{|l|}{ Mobility } \\
\hline None & 3 & 10 & \\
\hline moderate & 13 & 15 & \\
\hline Severe & 4 & 0 & \\
\hline \multicolumn{4}{|l|}{ Self-care } \\
\hline None & 10 & 23 & \\
\hline moderate & 9 & 1 & \\
\hline Severe & 2 & 1 & \\
\hline \multicolumn{4}{|l|}{ Usual activity } \\
\hline None & 3 & 12 & \\
\hline moderate & 10 & 10 & \\
\hline Severe & 8 & 3 & \\
\hline \multicolumn{4}{|l|}{ Pain/discomfort } \\
\hline None & 0 & 5 & \\
\hline moderate & 4 & 15 & \\
\hline Severe & 17 & 5 & \\
\hline Anxiety/depression & & & \\
\hline
\end{tabular}




\begin{tabular}{|lll|} 
None & 10 & 16 \\
\hline moderate & 6 & 6 \\
\hline Severe & 5 & 3 \\
\hline Total EQ 5D score & $10.47 \pm 2.19$ & $7.84 \pm 2.33$ \\
\hline
\end{tabular}

Figures 


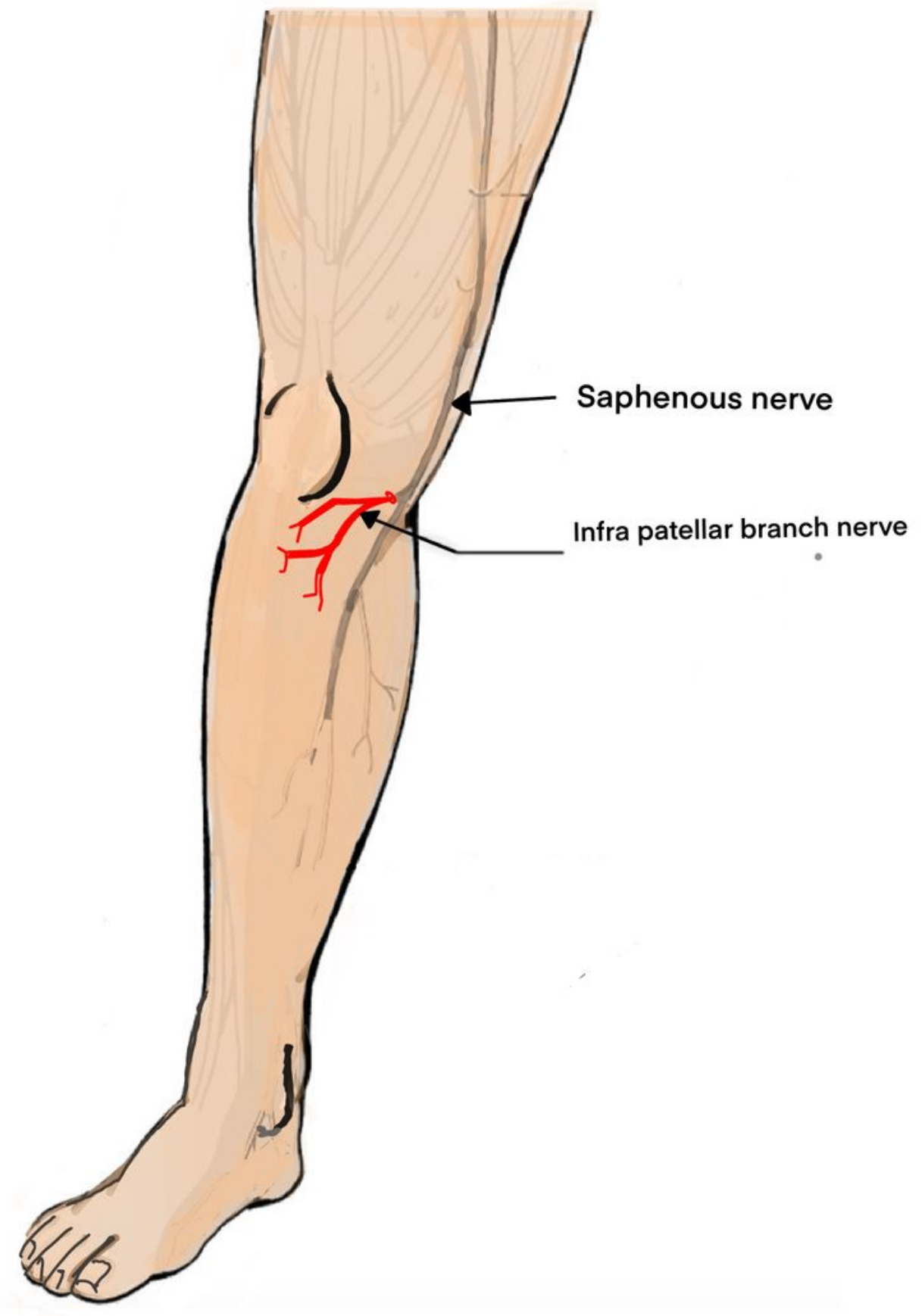

Figure 1

Schematic representation of the saphenous and the IPSBN. 

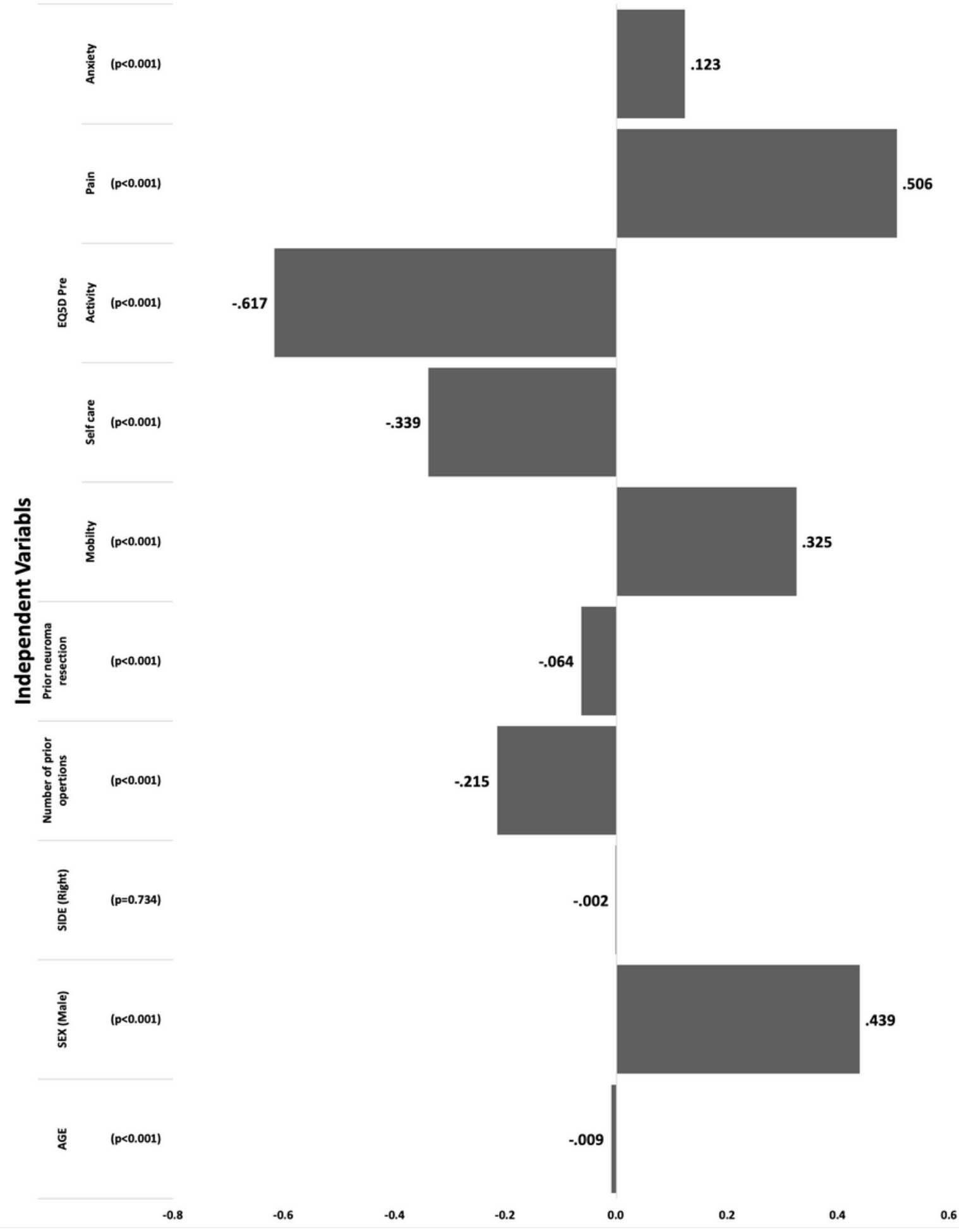

Figure 2

Coefficiency of independent variables on NRS pain difference following surgery. 


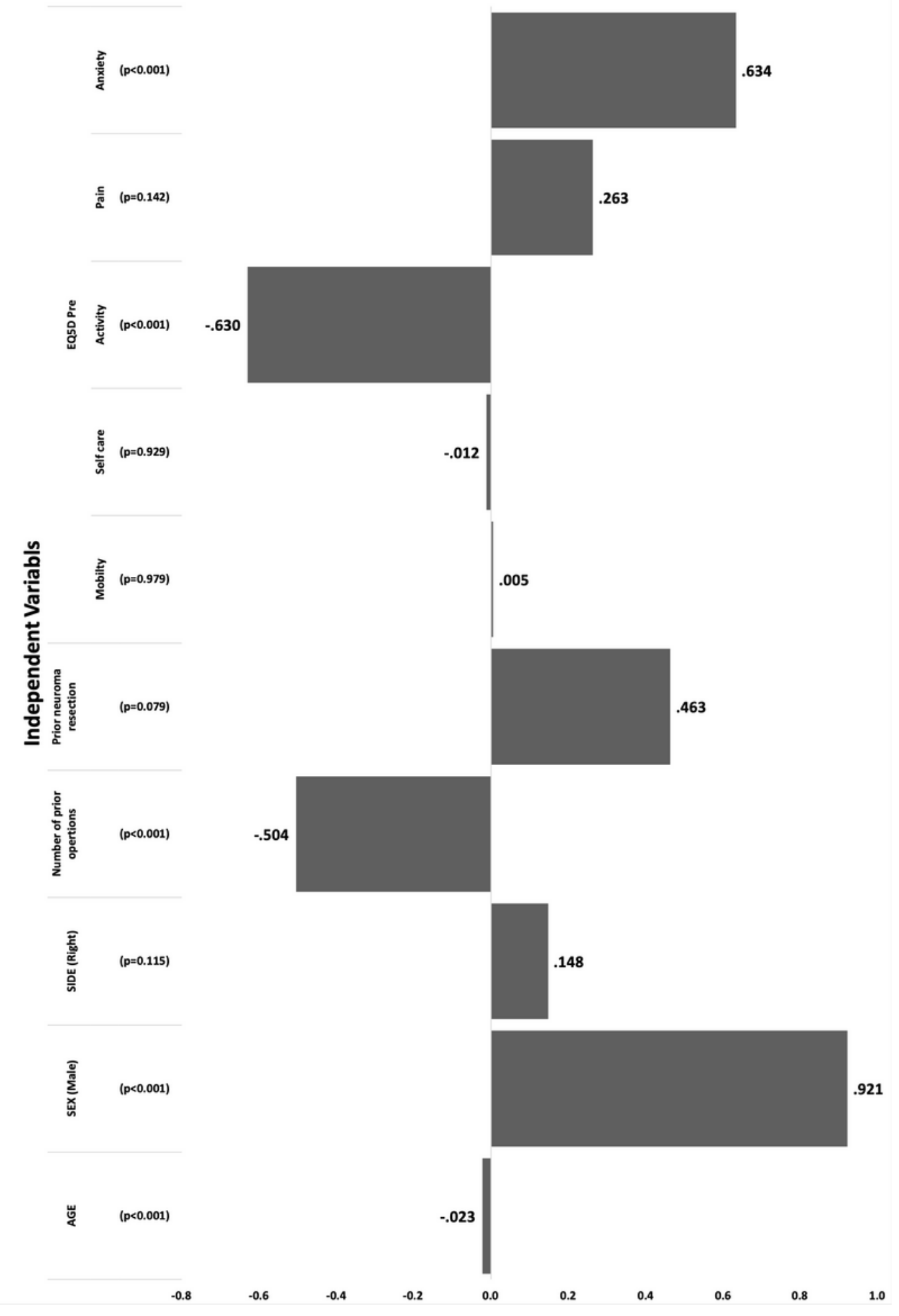

Figure 3

Coefficiency of independent variables on EQ-5D difference following surgery. 